\title{
Aplicação da fermentação em estado sólido sobre o farelo de cacau (Theobroma Cacao L.): Obtenção de ligninases
}

\author{
Application of solid state fermentation on the cocoa bran \\ (Theobroma Cacao L.): producing ligninases
}

\author{
Tamires Carvalho dos Santos ${ }^{1}$; George Abreu Filho ${ }^{2}$; Thiago José Onorio Rocha ${ }^{3}$; \\ Marcelo Franco ${ }^{4}$
}

\section{Resumo}

O objetivo deste trabalho foi analisar e quantificar a atividade cinética das enzimas ligninases: lacase, lignina peroxidase e Mn peroxidase, produzidas através de Fermentação em Estado Sólido. Utilizouse a espécie fúngica Aspergillus niger como inoculante e o resíduo proveniente do beneficiamento do cacau (Theobroma Cacao L.) como matéria prima, em diferentes concentrações de água. O resíduo agroindustrial, depois de gerado, necessita de destino adequado, pois, além de criar potenciais problemas ambientais, representa perdas de matérias-primas e energia, exigindo investimentos significativos em tratamentos para controlar a poluição. Foram avaliados o potencial da atividade cinética das enzimas estudadas em função das condições de tempo (24, 72, e 120 horas) e teor de água ( $40 \%, 50 \%$ e 60\%). A fermentação foi realizada a $30 \mathrm{oC}$ em estufa bacteriológica. Os resultados encontrados indicam a maximização da atividade enzimática ocorreu em 72 horas de fermentação e com $50 \%$ de teor de água, para todas as enzimas.

Palavras-chave: Aspergillus niger. Sustentabilidade ambiental. Biotransformação.

\begin{abstract}
The aim of this study was to analyze and quantify the kinetic activity of enzymes ligninases laccase, lignin peroxidase and manganese peroxidase, produced by Solid State Fermentation. We used the fungus Aspergillus niger as inoculum and the waste from the processing of cocoa (Theobroma Cacao L.) as raw material at different water concentrations. The agro-industrial residue, after generated, you need to target appropriate because, in addition to creating potential environmental problems, represents losses of raw materials and energy, requiring significant investments in treatments to control pollution. We evaluated the potential of kinetic activity of enzymes depending on weather conditions $(24,72$, and 120 hours) and water content $(40 \%, 50 \%$ and $60 \%)$. The fermentation was conducted at $300 \mathrm{C}$ in a bacteriological incubator. The results indicate the maximization of enzyme activity occurred within 72 hours of fermentation and 50\% water content, for all the enzymes.
\end{abstract}

Keywords: Aspergillus niger. Environmental sustainability. Biotransformation.

1 Graduando em Engenharia Ambiental, Universidade Estadual do Sudoeste da Bahia; eng.tamirescarvalho@yahoo.com.br.

2 Graduando em Zootecnia, Universidade Estadual do Sudoeste da Bahia.

3 Graduando em Licenciatura em Química, Universidade Estadual do Sudoeste da Bahia.

4 Professor Adjunto do Departamento de Estudos Básicos e Instrumentais, Universidade Estadual do Sudoeste da Bahia DEBIUESB; marcelofranco@pq.cnpq.br. 


\section{Introdução}

A crescente preocupação com o meio ambiente incentiva a viabilização de projetos que levam à sustentabilidade do sistema de produção industrial. A indústria de alimentos produz uma série de resíduos com alta capacidade de re-utilização. Com isso, minimiza-se o impacto ambiental destes tipos de indústrias na região onde estão situadas e ainda agrega-se valor aos produtos do mercado (PELIZER; PONTIERI; MORAES, 2007).

No Brasil, a fruticultura produz uma grande quantidade de subprodutos, tais como bagaços, farelos, cascas e sementes. Seu reaproveitamento como matéria-prima é viável devido ao seu baixo custo econômico (SOCCOL; VANDENBERGH, 2003; COUTO; SANROMAN, 2006; SÁNCHEZ; CARDONA, 2008). A industrialização do cacau (Theobroma cacao L.) gera grande quantidade de subprodutos. O farelo do cacau é constituído basicamente do processamento da amêndoa seca, sendo este uma excelente fonte lignocelulósica (ALMEIDA; ANTÔNIO NETO, 2000). A lignina é um composto formado por fenilpropanóides depositado durante a maturação da parede celular. Este composto faz ligações cruzadas com os polissacarídeos da parede auxiliando no seu empacotamento. O complexo formado por lignina, celulose e hemicelulose é denominado ligninocelulose (BUCHANAN; GRUISSEM; JONES, 2000).

$\mathrm{Na}$ natureza, existe uma grande variedade de microrganismos celulolíticos, entretanto apenas alguns são conhecidos como verdadeiros celulolíticos, isto é, são capazes de produzir celulases (ROWELL et al., 2007). As celulases livres podem ser produzidas por fungos ou bactérias, sendo que as enzimas fúngicas dominam as aplicações comerciais, devido ao seu alto nível de expressão e secreção (CHANG, 2007). Dentre eles, os fungos filamentosos, como o Aspergillus níger, possuem um grande potencial na degradação de compostos lignocelulósicos, já que requerem pouca água para seu desenvolvimento, o que representa menos efluente gerado, como também a economia de água durante o processo.

Os fungos constituem um dos grupos de microrganismos mais importantes na atividade de decomposição da matéria orgânica em função de sua capacidade especializada de degradação. Esta atividade ocorre, sobretudo, através de sua fase vegetativa ou miceliana. Nas fases vegetativa e reprodutiva, a formação de biomassa depende da produção de enzimas extracelulares, que são fundamentais na degradação dos componentes dos substratos, principalmente lignocelulose (VELÁZQUEZ-CEDEÑO; MATA; SAVOIE, 2002).

Durante a decomposição de compostos lignocelulósicos por fungos, seus componentes dependem de um efetivo e progressivo processo de despolimerização da lignina que dá origem a compostos de baixa massa molar susceptíveis ao metabolismo intracelular dos fungos. Isso ocorre por meio da ação de uma série de enzimas e compostos de baixa massa molecular extracelular (onde o início da degradação ocorre necessariamente de forma extracelular). Algumas das aplicações desses microorganismos que degradam a lignina incluem a polpação, branqueamento de polpas, liberação de carboidratos, conversão desses componentes em rações animais e tratamentos de resíduos derivados de lignina (ESPOSITO; AZEVEDO, 2004; FERRAZ, 2004).

$\mathrm{Na}$ biodegradação da lignina, essencial na ciclagem do carbono, diversas enzimas estão envolvidas. Elas podem ser agrupadas em fenoloxidases e enzimas que produzem peróxido de hidrogênio. As fenoloxidades são enzimas que pertencem às metaloproteínas, e podem ser divididas em dois subgrupos. Um grupo contém as enzimas dependentes de peróxido ou peroxidades, que incluem a lignina peroxidase (LiP) e a peroxidase dependente de manganês (MnP). O outro subgrupo contém as lacases que são cuproproteínas e não 
dependem de peróxido para atuar (FERRAZ, 2004).

A degradação da lignina pode ser entendida como um processo multienzimático por reação não específica, resultante da ação coordenada de uma série de enzimas ligninolíticas intra e extracelulares que desestabilizam as ligações da macromolécula, causando assim seu colapso (LEE; MOON, 2003; MANE et al., 2007). Cameron, Tomifeevski, Aust (2000) relataram que o melhor mecanismo estudado de degradação de lignina é o do basidiomiceto Phanerochaete chrysosporium. Através desses estudos foi possível propor que as enzimas relacionadas à degradação da lignina são agrupadas em duas classes distintas: fenoloxidases e enzimas que produzem peróxido de hidrogênio (FUJIAN; HONGZHANG; ZUOHU; 2001).

As duas principais estratégias para a produção de enzimas são a fermentação no estado sólido (FES) e a fermentação submersa (FS), que diferem entre si em relação a suas condições ambientais e formas de condução. Indiscutivelmente, um dos parâmetros mais exaltados na diferenciação desses dois tipos de processos é o teor de água presente no meio reacional. Na FES há ausência ou a quase ausência de água livre (PANDEY, 2003; RAGHAVARAO; RANGANATHAN, KARANTH, 2003). A água presente nesses sistemas encontra-se complexada com a matriz sólida de substrato ou como uma fina camada absorvida na superfície das partículas. Em geral, nesses processos o teor de água varia entre $30-85 \%$ e a atividade de água típica vai de 0,40 - 0,99, o que mimetiza condições encontradas na natureza e permite que sejam conduzidos sem prévia esterilização, visto que a contaminação, pelo menos por bactérias, é pouco provável (ROBINSON; NIGAM, 2003).

O objetivo deste trabalho é estudar o efeito do teor de água e do tempo de fermentação sobre a produção das enzimas Lacase, Lignina Peroxidase e Mn Peroxidase, responsáveis pela degradação da lignina no farelo de cacau, através da FES com auxílio do fungo filamentoso Aspergillus niger.

\section{Materiais e Métodos}

\section{Coleta e pré-processamento do resíduo}

O resíduo foi cedido por uma agroindústria de beneficiamento de polpa de frutas localizada na região sudoeste da Bahia, seco em estufa de secagem e esterilização $\mathrm{SOLAB}$ a $70{ }^{\circ} \mathrm{C}$ por 24 horas, a umidade obtida após a secagem foi estabelecida a 3\% em determinador de umidade inicial . O resíduo foi triturado em moinho de facas tipo Wiley ACB LABOR, após o processo de trituração o resíduo foi peneirado a uma granulométrica aproximada de 30 mesh, o que representa 0,6 a 0,7 $\mathrm{mm}$ de diâmetro para cada partícula.

\section{Obtenção da Solução de Esporos}

O microrganismo estudado foi o fungo filamentoso Aspergillus niger, proveniente do Laboratório de Reaproveitamento de Resíduos Agroindustriais - LABRA da UESB, campus de Itapetinga. A cultura esporulada (em PDA HIMEDIA acidificado) foi suspensa em solução de Tween 80 VETEC a 0,01\%, sendo nesta efetuada a contagem do número de esporos em suspensão, utilizando câmara de Neubauer dupla espelhada e microscópio binocular BIOVAL L1000.

\section{Fermentação em Estado Sólido}

As fermentações foram realizadas em erlenmeyers contendo $10 \mathrm{~g}$ de resíduo a este foi adicionando a suspensão de $10^{8}$ esporos por grama de substrato, na sequência foram adicionados volumes de água estéril até os seguintes teores de água: $40 \%, 50 \%$ e $60 \%$, estes foram quantificados experimentalmente. $\mathrm{O}$ teor de água do resíduo triturado foi de $6,34 \%$ este foi quantificado através do determinador de umidade infra-vermelho MARTE ID200. Os cultivos foram conduzidos a 30 ${ }^{\circ} \mathrm{C}$ em estufa bacteriológica modelo SL 101 SOLAB 


\section{Extração dos compostos enzimáticos}

Após o processo fermentativo, foi feita a extração mecânica do extrato enzimático com solução tampão de citrato de sódio VETEC com pH 4,8 a 50 mM. O extrato enzimático proveniente da fermentação foi recolhido e centrifugado a $1000 \mathrm{rpm}$ por 10 minutos em centrifuga CETRIBIO modelo 80-2B.

\section{Determinação dos compostos enzimáticos}

\section{Lacase}

A atividade da lacase foi realizada segundo o protocolo de Szklarz et. al (1989). Foram utilizados dois tubos de ensaio de $10 \times 100 \mathrm{~mm}$, um para amostra não fervida e outro para amostra fervida. Foi adicionado em cada tubo $0,6 \mathrm{~mL}$ da amostra a ser analisada e $0,3 \mathrm{~mL}$ do tampão citrato-fosfato. Um tubo foi fervido por 10 minutos (controle) e depois retirado e resfriado. O tempo inicial (zero) foi determinado como a medição da absorbância no momento em que se adiciona $0,1 \mathrm{~mL}$ de siringaldazina. Depois foi feita outra medição no tempo final, depois de 10 minutos. $1,0 \mathrm{~mL}$ de cada tubo contendo as amostras fervidas e não fervidas foram medidas contra espectro zero a $525 \mathrm{~nm}(\varepsilon=$ $\left.44600 \mathrm{~L} \cdot \mathrm{M}^{-1} \cdot \mathrm{cm}^{-1}\right)$.

\section{Lignina Peroxidase (LiP)}

A atividade da Lignina Peroxidase foi realizada segundo o protocolo de Archibald (1992). Foram utilizados dois tubos de ensaio de $10 \times 100 \mathrm{~mm}$, um para amostra não fervida e outro para amostra fervida. Foi adicionado em cada tubo $0,6 \mathrm{~mL}$ da amostra a ser analisada, $0,2 \mathrm{~mL}$ do tampão citratofosfato e $0,1 \mathrm{~mL}$ de $\mathrm{H}_{2} \mathrm{O}_{2}$. Um tubo foi fervido por 10 minutos (controle) e depois retirado e resfriado. O tempo inicial (zero) foi determinado como a medição da absorbância no momento em que se adiciona $0,1 \mathrm{~mL}$ de siringaldazina. Depois foi feita outra medição no tempo final após 10 minutos. Foram retirados alíquotas de $1,0 \mathrm{~mL}$ de cada tubo, medidas contra espectro zero a 460nm $(\varepsilon=29400$ L. $\left.\mathrm{M}^{-1} \cdot \mathrm{cm}^{-1}\right)$.

\section{Manganês Peroxidase (MnP)}

A atividade da $\mathrm{MnP}$ foi realizada segundo o Anastasi (2009). Foram utilizados dois tubos de ensaio de $10 \times 100 \mathrm{~mm}$, um para amostra não fervida em H2O2 em tampão succinato, $100 \mu \mathrm{L}$ de lactato de sódio, $200 \mu \mathrm{L}$ de albumina bovina e $600 \mu \mathrm{L}$ de sobrenadante (amostra). Um tubo foi fervido por 10 minutos (controle) e depois retirado e resfriado. O tempo inicial (zero) foi determinado como a medição da absorbância no momento em que se adiciona $0,1 \mathrm{~mL}$ de vermelho fenol. Depois de 10 minutos, o tempo final foi determinado com a medição após adicionar $40 \mu \mathrm{L}$ de $\mathrm{NaOH}$ para parar a reação. $1,0 \mathrm{~mL}$ de cada tubo contendo as amostras fervidas e não fervidas foram medidas contra espectro zero a $610 \mathrm{~nm}\left(\varepsilon=65000 \mathrm{~L} \cdot \mathrm{M}^{-1} \cdot \mathrm{cm}^{-1}\right)$.

\section{Cálculo das atividades lignolíticas}

A atividade cinética de produção das enzimas foi calculada seguindo a equação descrita por Aguiar Filho (2008).

$$
\mathrm{UI} / \mathrm{L}=\frac{\Delta \mathrm{Abs}}{\varepsilon \times \mathrm{R} \times \mathrm{t}} \times 10^{6}
$$

Onde:

$$
\begin{aligned}
& \Delta \text { Abs }=\text { absorbância (Abs final }- \text { Abs inicial) } \\
& \varepsilon=\text { coeficiente de absorção molar } \\
& \mathrm{R}=\text { quantidade de solução da amostra } \\
& \mathrm{t}=\text { tempo de reação em minutos } \\
& \mathrm{UI} / \mathrm{L}=\text { Unidade Internacional }
\end{aligned}
$$




\section{Análises dos resultados}

Os experimentos foram realizados em triplicata bem como as dosagens. Os resultados finais foram obtidos através da diferença entre as médias de três repetições experimentais.

\section{Resultados e Discussão}

Durante o processo de fermentação em estado sólido ocorre à sacarificação, esse processo consiste na conversão enzimática de polissacarídeos em açúcares fermentáveis. O efeito do teor de água e do tempo de fermentação sobre as atividades cinéticas das enzimas estudadas estão demonstradas nas figuras 1, 2 e 3. A maximização da produção de todas as enzimas ocorre no teor de água de $50 \%$ e a 72 horas de fermentação, todas a 30 0C. Os valores máximos para a Xilanase, Lignina Peroxidase e Mn Peroxidase obtidos foram respectivamente $8,49 \times 10^{13} \mathrm{UI} / \mathrm{L}, 8,44 \times 10^{12} \mathrm{UI} / \mathrm{L}$ e $1,79 \times 10^{11} \mathrm{UI} / \mathrm{L}$.

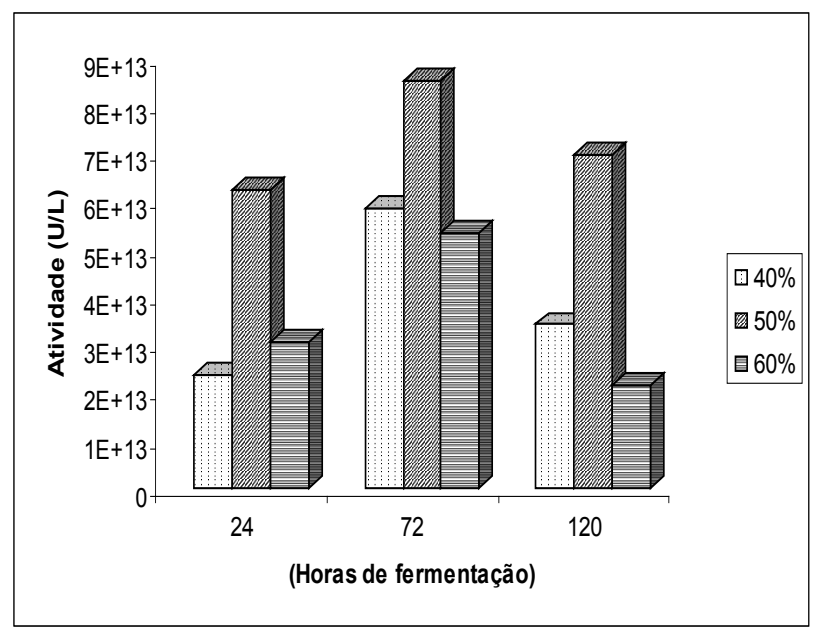

Figura 1. Atividade de Lacase com variação do tempo de fermentação e teor de água

As Lacases atuam diretamente sobre as estruturas fenólicas através da oxidação dos fenóis pela abstração de um elétron mediada pela redução de $\mathrm{Cu}^{2+}$ a $\mathrm{Cu}^{+}$, que, por sua vez, reduz $\mathrm{O}_{2}$ a $\mathrm{H}_{2} \mathrm{O}$, permitindo que a enzima atue de forma cíclica (FERRAZ, 2004). O que pode ser constato na produção obtida no trabalho, onde a atividade desta enzima foi a mais notória em produção em 72 horas de processo fermentativo, já que o período de atuação desta é maior em relação às outras, atuando de forma continuada durante a fermentação em estado solido. 


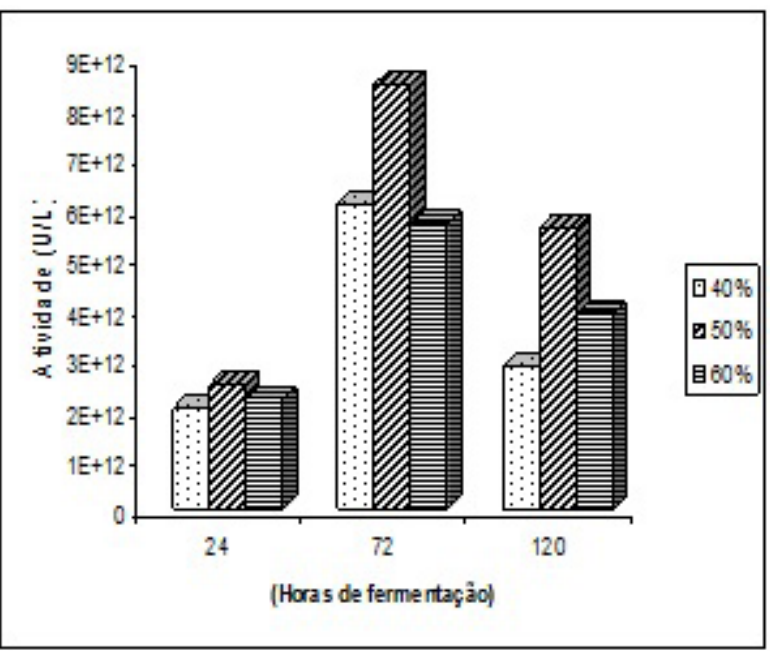

Figura 2. Atividade de Lignina Peroxidase com variação do tempo de fermentação e teor de água.

LiPs são heme-proteínas que apresentam para abstrair elétrons de estruturas aromáticas não potencial de oxidação suficientemente elevado fenólicas, dando origem a radicais cátions.



Figura 3. Atividade de Mn Peroxidase com variação do tempo de fermentação e teor de água.

As Mn Peroxidases também são hemeproteínas, porém, são enzimas dependentes de $\mathrm{Mn}^{2+}$ e apresentam potencial de oxidação suficiente somente para abstrair elétrons de estruturas fenólicas. Primeiramente, a MnP é ativada pela oxidação por $\mathrm{H}_{2} \mathrm{O}_{2}$, levando à formação do composto I (CI). A redução de CI a C0 ocorre em duas etapas. Na primeira etapa, o composto I pode ser reduzido a composto II à custa da oxidação de uma estrutura fenólica ou de $\mathrm{Mn}^{2+}$. Na segunda etapa, o composto II é reduzido ao seu estado nativo $(\mathrm{C} 0)$, exclusivamente à custa de um elétron proveniente de um íon $\mathrm{Mn}^{2+}$. Por outro lado, o $\mathrm{Mn}^{3+}$ formado é bastante reativo e normalmente é estabilizado por quelantes produzidos pelo próprio fungo, como o ácido oxálico. O complexo $\mathrm{Mn}^{3+}$-oxalato, por sua vez, pode ser reduzido à custa da oxidação de outra estrutura fenólica (FERRAZ, 2004). Pode ser observado que os valores encontrados para a $\mathrm{Mn}$ Peroxidase e Lignina Peroxidase, foram próximas fato que deve estar relacionada ao conjunto 
estrutural ou arranjo estrutural do resíduo, ou ainda a formação de compostos fenólicos durante a fermentação que induzem estas duas enzimas.

Todos os valores encontrados na literatura para ambas as enzimas descritas acima são inferiores aos aqui demonstrados. Abaixo segue uma tabela (Tabela 1.) comparativa dos resultados para as enzimas aqui estudadas, valores quantificados por pesquisadores atuais.

Tabela 1 - Valores comparativos encontrados em demais pesquisas para enzimas lignolíticas.

\begin{tabular}{|c|c|c|c|c|}
\hline Autor & Enzima & Substrato & Microrganismo & Atividade \\
\hline BETTIN et al. 2009. & Lacase & $\begin{array}{c}\text { Caseína em } \\
\text { diferentes } \\
\text { concentrações }\end{array}$ & $\begin{array}{c}\text { P. sajor caju (PS- } \\
2001\end{array}$ & $11300,0 \mathrm{UI} / \mathrm{L}$ \\
\hline FERREIRA, 2009. & Lacase & Vinhaça & P. sajor-caju & $450 \mathrm{UI} / \mathrm{L}$ \\
\hline Este trabalho & Lacase & Farelo de Cacau & Aspergillus niger & $8,44 \times 10^{12} \mathrm{UI} / \mathrm{L}$ \\
\hline GOMES et al.2009. & Lignina peroxidase & Corantes industriais & Basidiomycetes & $9 \mathrm{U} / \mathrm{mL}$ \\
\hline ANASTASI et al. 2009. & Lignina peroxidase & Arroz & Basidiomycetes & $19 \mathrm{U} / \mathrm{L}$ \\
\hline Este trabalho & Lignina peroxidase & Farelo de Cacau & Aspergillus niger & $8,49 \times 10^{13} \mathrm{UI} / \mathrm{L}$ \\
\hline GOMES et al. 2009 . & Mn peroxidase & Corantes industriais & Basidiomycetes & $0,6 \mathrm{U} / \mathrm{mL}$ \\
\hline ANASTASI et al. 2009. & Mn peroxidase & Arroz & Basidiomycetes & $124 \mathrm{U} / \mathrm{L}$ \\
\hline Este trabalho & Mn peroxidase & Farelo de Cacau & Aspergillus niger & $1,79 \times 10^{11} \mathrm{UI} / \mathrm{L}$ \\
\hline
\end{tabular}

A umidade é um fator crítico para o crescimento de fungos em substrato sólido. Como a quantidade de água é sempre limitada, o controle do nível de umidade é essencial para a otimização do processo em estado sólido. $\mathrm{O}$ teor de água adequada para o substrato deve permitir a formação de um filme de água na superfície, para facilitar a dissolução e a transferência de nutrientes e oxigênio. Entretanto, os espaços entre as partículas devem permanecer livres para permitir a difusão de oxigênio e a dissipação de calor (GERVAIS; MOLIN, 2003; SANCHEZ, 2009). O que se pode notar que o teor de água de $50 \%$ foi à ideal para a obtenção das enzimas aqui estudadas, a otimização realizada foi necessária para o ajuste de produção da enzima. Nos teores de água estudados, 40\% e 60\%, ocorreu a diminuição da produção enzimática este fato pode estar relacionado com a inibição do fungo, marcado pela extrapolação do nível do teor de áuga ideal para o desenvolvimento da linhagem selecionada no caso de $60 \%$, ou a baixa atividade de água necessaria para que o fungo consiga se desenvolver, estas duas condições podem estar influenciando no metabolismo responsável pela produção da enzima.

O decréscimo na atividade da enzima com o aumento do tempo de incubação pode ser devido à produção de co-produtos resultante do metabolismo microbiano, além do esgotamento de nutrientes, inibindo o crescimento do fungo e a formação da enzima (GUPTA, 2010; SHAFIQUE, 2009). Enzimas geralmente apresentam mecanismo de controle da expressão que podem ser estimulados ou inibidos por produtos do meio. Os produtos finais de uma dada via metabólica são frequentemente inibidores das enzimas que catalisam os primeiros passos da via. Esse mecanismo é conhecido como Feedback negativo ou autoalimentação (WHITAKER, 1994). Biazus et al. (2006), observaram que a produção de enzimas, à princípio, é lenta, acelerando até alcançar seu valor máximo, a partir desse momento, a presença de metabólitos secundários promove a inibição na excreção enzimática promovendo 
a redução na atividade enzimática (DANTAS, 2002; SANTANA 2002), este processo também foi observado no presente trabalho. Omemu et al., 2005 obtiveram maior rendimento de hidrólise do amido de mandioca por A. niger após 72 horas de fermentação, concordando com Alva et al., 2007 que também relataram uma maior atividade enzimática por Aspergillus. Resultados similares ao presente trabalho.

O fungo sintetizou a enzima sem a necessidade de qualquer indutor ou suprimento além do resíduo de cacau e água em diferentes concentrações, demonstrando assim que as enzimas são constitutivas.

\section{Conclusões}

No que se diz respeito à obtenção de enzimas lignolíticas a estirpe de Aspergilus niger mostrara bastante promissora, na análise realizada a Lacase obteve um maior destaque de produção em relação às demais enzimas aqui estudadas. Em todas as enzimas estudas o teor de água para a melhor atividade cinética foi $50 \%$ com o tempo de fermentação de 72 horas. Em todos os trabalhos citados anteriormente os tempos de incubação variaram de 7 a 15 dias, bem maiores que aqueles utilizados em nosso trabalho, é importante também ressaltar que não foi utilizado nem um tipo de indutor, suprimento ou pré hidrólise no resíduo, demonstrando assim que as enzimas são constitutivas. A FES é uma tecnologia capaz de propor caminhos alternativos para a reutilização dos resíduos gerados, diminuindo passivos ambientais bem como a valorização econômica desses rejeitos.

\section{Agradecimentos}

Os autores agradecem ao Conselho Nacional de Desenvolvimento Científico e Tecnológico (CNPq) pela bolsa de ITI (Iniciação Tecnológica Industrial) concedida e ao Banco do Nordeste
(BNB) pelo apoio financeiro concedido.

\section{Referência}

AGUIAR FILHO, J. M. M.. Análise enzimática de fungos lignocelulolíticos cultivados em vinhaça $e$ bagaço de cana- de açúcar. Dissertação (Mestrado em Agricultura Microbiologica) - Universidade de São Paulo, Escola Superior de Agricultura Luiz de Queiroz, Piracicaba, 2008.

ALMEIDA, C. M. V. C.; ANTONIO NETO, F. Custos de produção de sementes de variedades hibridas de caca em Rondônia. Agrotrópica, Itabuna, v. 12, p. 129-134, 2000.

ALVA, S.; ANUPAMA, J.; SAVLA, J.; CHIU, Y. Y; VYSHALI, P.; SHRUTI, M.; YOGEETHA, B. S.; BHAVYA D.; PURVI, J.; RUCHI, K.; KUMUDINI, B. S.; VARALAKSHMI, K. N. Production and characterization of fungal amylase enzyme isolated from Aspergillus sp. JGI 12 in solid state culture. African Journal of Biotechnology, v. 6, n. 5, p. 576-581, Jan. 2007.

ANASTASI, A.; COPPOLA, T.; PRIGIONE, V.; VARESE, G. C. Pyrene degradation and detoxification in soil by a consortium of basidiomycetes isolated from compost: role of laccases and peroxidases. Journal of Harzardous Materials, v. 165, p. 1229-1233, 2009.

ARCHIBALD, F. S. A new assay for lignin-type peroxidases employing the dye azure B. Applied and Environmental Microbiology, Washington, v. 58, n. 9, p. 3110-3116, 1992.

BETTIN, F.; MONTANARI, Q.; CALLONI, R.; GAIO, T.A.; SILVEIRA, M.M.; DILLON, A.J.P. Production of laccases in submerged process by Pleurotus sajorcaju PS-2001 in relation to carbon and organic nitrogen sources, antifoams and Tween 80. World Journal Microbiology and Biotechnology, v. 36, n. 1, p. 1-9, 2009.

BIAZUS, J. P. M.; SOUZA, R. R.; SANTANA, J. C. C.; TAMBOURGI, E. B. Otimização da secagem do malte de Zea mays. Ciência e Tecnologia de Alimentos, v. 26, n. 4, p. 787-792, 2006.

BUCHANAN, B. B.; GRUISSEM, W.; JONES, R. L. (Ed.). Biochemistry \& molecular biology of plants. Rockville: American Society of Plant Physiologists, 2000. 1387 p.

CAMERON, M. D.; TOMIFEEVSKI, S.; AUST, D. S. Enzimology of Phanerochaete chrysosporium with respect to the degradation of recalcitrant compounds and 
xenobiotics. Applied and Environmental Microbiology, v. 54, p. 751-758, 2000.

CHANG, M. Harnessing energy from plant biomass. Current Opinion in Chemical Biology, v. 11, p. 677684, 2007.

COUTO, S. R.; SANROMAN, M. A. Application of solid-state fermentation to food industry, A Review. Journal of Food Enginnering, v. 76, p. 291-302, 2006.

DANTAS, B. F. Atividade amilolítica e qualidade de sementes de milho (Zea mays L.) submetidas ao alagamento. Tese (Doutorado em Agricultura)Faculdade de Ciências Agronômicas, Universidade Estadual Paulista Júlio de Mesquita Filho, Botucatu, 2002.

ESPOSITO, E.; AZEVEDO, J. L. Fungos: uma introdução à biologia, bioquímica e biotecnologia. Caxias do Sul: EDUCS, 2004.

FERRAZ, A. Fungos decompositores de materiais lignocelulósicos. In: ESPOSITO, E.; ZEVEDO, J. L. Fungos: uma introdução à biologia, bioquímica e biotecnologia. Caxias do Sul: EDUCS, 2004. p. 215242.

FERREIRA, L. F. R. Biodegradação de vinhaça proveniente do processo industrial de cana-de-açúcar por. Tese (Doutorado em Agricultura). Escola Superior de Agricultura Luiz de Queiroz, Piracicaba, 2009.

FUJIAN, X.; HONGZHANG, C.; ZUOHU, L. Solidstate production of lignin peroxidase (LiP) and manganese peroxidase $(\mathrm{MnP})$ by Phanerochaete chrysosporium using steam-exploded straw as substrate. Bioresource Technology, v. 80, n. 2, p. 149-151, 2001.

GERVAIS, P.; MOLIN, P. The role of water in solidstate fermentation. Biochemical Engineering Journal. v. 13, n. 1, p. 85-1, 2003.

GOMES, E.; AGUIAR, A. P.; CARVALHO, C. C.; BONFÁ, M. R. B.; SILVA, R.; BOSCOLO, M. Ligninases production by basidiomycetes strains on lignocellulosic agricultural residues and their application in the decolorization of synthetic dyes. Brazilian Journal of microbiology, v. 40, p. 31-39, 2009.

GUPTA, A.; GAUTAM, N.; MODI, D. R. Optimization of a-amylase production from free and immobilized cells of Aspergillus niger. Journal of Biotechnology and Pharmaceutical Research, v. 1, n. 1, p. 1-8, 2010.

LEE, K.; MOON, S. H. Electroenzymatic oxidation of veratryl alcohol by lignin peroxidase. Journal of Biotechnology, Amsterdam, v. 102, p. 261-268, 2003.

OMEMU, A. M.; AKPAN, I.; BANKOLE, M. O.; TENIOLA, O. D. Hydrolysis of raw tuber starches by amylase of Aspergillus niger AM07 isolated from the soil. African Journal of Biotechnology, v. 4, n. 1, p. 1925, 2005.

PANDEY, A. Solid-state fermentation. Biochemical Engineering Jounal, v. 13, p. 81-84, 2003.

PELIZER, L. H.; PONTIERI, M. H.; MORAES, I. O. Utilização de resíduos agro-industriais em processos biotecnológicos como perspectiva de redução do impacto ambiental. Journal of Technology Management \& Innovation, v. 2, p. 118-127, 2007.

RAGHAVARAO, K. S. M. S.; RANGANATHAN, T. V.; KARANTH, N. G. Some engineering aspects of solidstate fermentation. Biochemical Engineering Jounal. v. 13, p. 127-135, 2003.

ROBINSON, T.; NIGAM, P. Bioreactor design for protein enrichment of agricultural residue by solid state fermentation. Biochemical Engineering Journal, v. 13, p. 197-203, 2003.

ROWELL, M. R.; PETTERSEN, R.; HAN, J. S.; ROWELL, J. S.; TSHABALALA, M. A. Cell wall chemistry In: ROWELL, R. M. (Ed.). Handbook of wood chemistry and wood composites. Champagne: CRC Press, 2007. 487 p.

SANCHEZ, C. Lignocellulosic residues: biodegradation and bioconversion by fungi. Biotechnology Advances, v. 27, n. 2185-94, 2009.

SÁNCHEZ, O. J.; CARDONA, C. A. Trends in biotechnological production of fuel ethanol from different feedstocks. Bioresource Technology, v. 99, p. 5270-5295, 2008.

SANTANA, J. C. C. Recuperação das enzimas a e b-amilases em sistema bifásico aquoso PEG/ CaCl2 para uso como biocatalizador amiláceos. Dissertação (Mestrado em Engenharia Química)- Faculdade de Engenharia Química, Universidade Estadual de Campinas, Campinas, 2002.

SHAFIQUE, S.; BAJWA, R.; SHAFIQUE, S. Screening of Aspergillus niger and A. flavus strains for extra cellular alpha-amylase activity. Pakistan Journal of Botanic, v. 41, n. 2, p. 897-905, 2009.

SOCCOL, C. R.; VANDENBERGHE, L. P. S. Overview of applied solid-state fermentation in Brazil. Biochemical Engineering Journal, v. 13, p. 205-218, 2003.

SZKLARZ, G.; ANTIBUS, R. K.; SINSABAUGH, R. L.; LINKINS, A. E. Production of phenoloxidases and peroxidases by wood-rotting fungi. Mycologia, New York, v. 81, p. 234-240, 1989.

VELAZQUEZ-CEDEÑO, M. A.; MATA, G.; SAVOIE, 
J. M. Waste reducing cultivation of Pleurotus ostreatus and Pleurotus pulmonarius on coffe pulpe changes in the production of some lignocellulolytics enzymes.

Word Journal of Microbiology and Biotechnology, v. 18, n. 3, p. 201-207, 2002.

WHITAKER, J. R. Principles of enzymology for the food sciences. 2. ed. Dekker: Boca Raton, 1994.

Recebido em 22 Fevereiro 2011-Received on February 22, 2011.

Aceito em 6 Abril, 2011 - Accepted on April 6, 2011. 